\title{
Letter visibility and the viewing position effect in visual word recognition
}

\author{
MICHAËL STEVENS \\ Ghent University, Ghent, Belgium \\ and \\ JONATHAN GRAINGER \\ CNRS and Université de Provence, Aix-en-Provence, France
}

\begin{abstract}
The ease with which printed words are recognized depends on the position at which the eyes initially fixate the word. In this study, we examined to what extent recognition performance for each fixation position depends on the average visibility of the word's constituent letters. Experiment 1 measured recognition performance to single letters embedded in strings of Xs (lengths of 5 and 7) for all combinations of letter position and initial fixation position in the string. In Experiment 2, recognition performance was measured for five-letter and seven-letter words as a function of initial fixation position in the word. Whereas average letter visibility showed a symmetric function in Experiment 1, the word recognition data of Experiment 2 showed the typical asymmetric curve. Combining the letter visibility data with measures of lexical constraint using absolute letter-in-string positions failed to capture the pattern in the word data. An alternative measure of constraint based on relative position coding of letters generated more accurate predictions.
\end{abstract}

During reading, the eye lands preferentially at certain positions in a word (Dunn-Rankin, 1978; Rayner, 1979). For long words, this position is somewhat to the left of the middle of the word, at least in English, a language that is read from left to right. Rayner referred to this as the preferred viewing location. One possible explanation for this phenomenon was provided by O'Regan (1981). According to this author, given the rapid drop in visual acuity with increasing distance from the center of vision (Anstis, 1974; R. J. Jacobs, 1979), maximal information about the letters of a word can be extracted when the middle of the word is fixated. O'Regan also suggested that effects of visibility could be modified by lexical factors. Given that the first part of a word generally provides more information about the identity of the word than does the last part, the most informative fixation should be left of the middle of the word, referred to as the convenient viewing position (VP). To provide a direct test of this hypothesis, O'Regan, LévySchoen, Pynte, and Brugaillère (1984) varied a stimulus word's horizontal location relative to an initial fixation point. This way, fixations on different positions in a word

The present work was carried out while the first author was visiting the Laboratoire de Psychologie Cognitive during a Socrates exchange program between the University of Ghent and the University of Provence. The authors thank André Vandierendonck for facilitating this initiative. Françoise Vitu, Ralph Radach, and Albrecht Inhoff provided excellent comments on a preliminary version of this work. Correspondence concerning this article should be addressed to J. Grainger, Laboratoire de Psychologie Cognitive, 29, Av. R. Schuman, 13621 Aix-en-Provence, France (e-mail: grainger@up.univ-mrs.fr). could be forced. In word-naming and word comparison tasks, reaction times were optimal when fixation was between the third and the fifth letters, for words that were 5-11 letters long. Naming and decision latencies increased 20-30 msec per letter deviation from this optimal viewing position. Comparable results were found using the lexical decision task (O'Regan \& Jacobs, 1992) and in a paradigm measuring eye refixation probability (McConkie, Kerr, Reddix,Zola, \& Jacobs, 1989). These studies clearly demonstrated that reading words in isolation is strongly influenced by the initial VP in the word. Vitu, O'Regan, and Mittau (1990) compared isolated word reading with reading continuous text and found a VP effect (measured in terms of refixation probability) in the text-reading situation. The effect was, however, weaker, and the optimum was slightly closer to the beginning of the word, as compared with the isolated word condition.

It therefore appears that the preferred VP in reading observed by Dunn-Rankin (1978) and Rayner (1979) could be the result of a strategy aimed at increasing reading efficiency by landing as often as possible at the position in the word that allows optimal processing (O'Regan, 1981). However, as we shall see below, the opposite argument can also be made (cf. Nazir, 2000), whereby optimal processing of isolated words is determined by how these words are typically fixated in normal reading. Thus, the preferred VP effect observed in unconstrained reading situations appears to be intimately related to the VP function obtained by forcing fixation at a given position in a word. However, these are not necessarily identical phenomena. In any case, there is one key characteristic shared by the distribution of 
landing sites in normal reading and the VP function obtained by experimental manipulation, which has attracted much attention in recent research. This is the asymmetric nature of the function, which has a marked bias toward word beginnings. When recognition performance is plotted against initial fixation position, an asymmetric inverse U-shaped function is obtained, with higher performance for fixations left of center than for those right of center (for experiments run in English and French). It is the asymmetric nature of the VP function that is the focus of the present study.

\section{ASYMMETRY IN THE VIEWING POSITION FUNCTION}

A number of studies have proposed and tested alternative explanations of the asymmetric function that relates initial fixation position to the ease with which isolated words are recognized (referred to hereafter as the $V P$ function). In the following, we will briefly examine each of these possible causes. Each of these explanations proposes a critical factor that generates an asymmetric VP function when combined with the basic effects of visual acuity.

\section{Hemispheric Specialization}

A part of the observed asymmetry may be caused by the location of brain structures involved in the processing of printed words. Information falling on the right visual field of both eyes is initially projected onto the left hemisphere of the brain, whereas information falling on the left visual field is projected onto the right hemisphere. Given that in most literate brains, lexical processing takes place in the left hemisphere, the information about the letters left of fixation is initially sent to the right hemisphere and has to be transmitted through the corpus callosum before arriving in the lexical processing system. This detour takes time and could, therefore, produce the observed asymmetry in the VP function. Some persons appear to have their lexical processing system located in the right hemisphere, as has been attested by studies in which differences in processing time for stimuli presented in the left or the right visual field have been examined. It would therefore be expected that the asymmetry in the VP function should be shifted in such people, with a preference for fixations toward the end of the word. This is what was found by Brysbaert (1994), but the difference between both types of hemispheric dominance was rather small.

\section{Asymmetry in the Perceptual Span}

Other authors have isolated reading direction as a possible causal factor. According to Rayner, Well, and Pollatsek (1980), for languages that are read from left to right, the perceptual span during reading extends further to the right (about 15 letters) than to the left (about 4 letters), whereas the opposite is true for languages that are read from right to left. Thus, for languages read from right to left, such as Arabic and Hebrew, the optimum of the VP curve should be shifted right of the center of the word. To examine this, Farid and Grainger (1996) compared the VP curves in French and Arabic. The typical leftward bias in the VP curve was found for French. For the Arabic words, however, the observed curve was rather symmetric. Reading direction indeed changed the optimal fixation location but did not actually reverse the asymmetry in the VP function.

\section{Asymmetry in Letter Visibility}

The third hypothesis, related to the preceding one, is that there is an asymmetry in the visibility of the letters left and right of fixation (Bouma, 1973; Kajii \& Osaka, 2000; Nazir, 1991; Nazir, Heller, \& Sussmann, 1992; Nazir, Jacobs, \& O'Regan, 1998). Nazir et al. (1992) measured letter visibility at various distances left and right of fixation. The drop of recognition performance depended not only on distance from fixation, but also on presentation side. At the same distance from fixation, letters right of fixation were easier to recognize than letters on the left. This asymmetry in letter perception had previously been reported by Bouma (1973) for the first and last letters of nonsense strings and has since been replicated for letters embedded in digits (Kajii \& Osaka, 2000). The confirmed asymmetry in letter visibility led Nazir et al. (1992) to conclude that the asymmetry in the VP function obtained with word stimuli is caused by variations in the visibility of the word's component letters: When more letters are to the left of fixation, overall letter visibility is lower than when there are more letters to the right of fixation. The present study shows that with more complete measures of letter visibility, ${ }^{1}$ there is, in fact, no such asymmetry in the function relating average letter visibility and initial fixation position.

In a more recent study, Nazir, Jacobs, and O'Regan (1998) put this hypothesis to a further test. Letter visibility was increased to compensate for the drop of acuity. To do this, "butterfly" words were used: Letters further away from fixation were presented with increasing font size. For five-letter words, this manipulation had the desired effect: Fixation position did not influence recognition performance. For longer words, however, an adverse effect of fixation on the second part of the word remained.

\section{Perceptual Learning}

Nazir (2000) advanced the hypothesis that the preferred landing position documented by Dunn-Rankin (1978) and Rayner (1979) is indeed the cause of the VP effect observed with isolated words. The distribution of landing sites in normal reading would, on the other hand, be the result of low-level visuo-oculomotor factors. Since the distribution of landing sites in normal reading resembles the VP function, the asymmetry in this function is explained as resulting from the frequency with which words have been seen at different fixation positions. The fixationdependent processing fluency obtained via manipulations of initial VP would result from a frequency-sensitive learning mechanism operating on visuo-orthographicrepresentations of words. According to this theoretical position, lexical constraint should not influence the VP function: Visual acuity and perceptual learning are the two necessary and sufficient causal factors. 


\section{Lexical Constraint}

When introducing the VP paradigm, O'Regan et al. (1984) already pointed to the fact that more words share the same final letters than the same initial letters (according to their statistical analysis of French). To see whether this influenced the location of the optimal viewing position, words with a unique beginning were compared with words with a unique end. The authors did not observe the expected shift in the asymmetry of the VP curve for unique-ending words, but end fixations did lead to improved recognition of these words, as compared with words with a unique beginning. This finding suggested that lexical ambiguity does influence the form of the VP curve but that it is not the only causal factor over and above effects of visual acuity. Comparable results were found by Holmes and O'Regan (1987). Both of these studies used relatively long words with the specific characteristic that they had six letters at either the beginning or the end that uniquely defined the word. Brysbaert, Vitu, and Schroyens (1996) used five-letter words with a unique trigram at the beginning or the end. Farid and Grainger (1996) used prefixed or suffixed words. All these studies found an influence of the information distribution in target words, but the only study to actually demonstrate a reversal in the asymmetry of the VP curve was the one performed by Farid and Grainger, using prefixed and suffixed Arabic words (see Deutsch \& Rayner, 1999, for a similar result in Hebrew).

The characteristics of a word's orthographic neighborhood $^{2}$ has also been shown to affect the VP function. Grainger (1990) showed that words with a single highfrequency orthographic neighbor are harder to recognize than words without such high-frequency neighbors. This neighborhood frequency effect was shown to interact with the VP effect by Grainger, O'Regan, Jacobs, and Segui (1992). Fixation on the disambiguating letter between a stimulus word and its more frequent neighbor reduced the neighborhood interference by about $50 \%$. When the disambiguating letter was the fourth letter of a five-letter word, there was no longer an advantage for fixations on the second letter, as compared with fixations on the fourth letter.

In the studies cited above, although influences of lexical constraint on the VP curve were found, the majority actually failed to reverse the VP curve asymmetry. According to a statistical analysis performed by Clark and O'Regan (1999), this failure could be due to the choice of the stimuli tested in these studies (an argument also put forward by Farid \& Grainger, 1996). Clark and O'Regan reasoned that on the basis of visual acuity, on the one hand, and lateral masking, on the other (e.g., Huckauf, Heller, \& Nazir, 1999), the four most visible letters in a given word will always be the two letters closest to fixation plus the two outer letters. Clark and O'Regan therefore defined the lexical ambiguity of a word as the number of words that have the same letters in these four positions and measured this for a large set of words, using computerized dictionaries of English and French. The curves of the mean ambiguities as a function of fixation position were found to be highly similar to the VP function observed in prior research. When fixation is just be- fore the middle of the word, relatively few words are compatible with the four given letters, but when fixation is more to the extremities of the word, ambiguity increases, since more and more words share the given set of letters. The theoretical analysis of Clark and O'Regan has not yet been tested empirically. It remains to be seen whether calculations of lexical constraint based on empirical measures of letter visibility can indeed account for the VP function.

\section{THE PRESENT STUDY}

The present study provides a further exploration of the role of letter visibility and lexical ambiguity as possible causes of the VP effect. Bouma (1973) tested identification of the initial and final letters of random letter strings (e.g., dvxmk) with the entire string presented in the left or the right visual field. Nazir et al. (1992) measured the visibility of letters embedded in a series of Xs. However, the letters did not appear at every possible position in the series, and fixation was only on the first or the last letter in the series. Kajii and Osaka (2000) measured identification of letters embedded in digits, but once again the entire string was presented left or right of a central fixation point (in their horizontal display condition). Finally, traditional studies of letter-in-string visibility (e.g., Estes, Allmeyer, \& Reder, 1976) used only central fixations. So to date, there are no studies providing complete measures of letter visibility across all combinations of fixation position and letter-in-string position. Our first experiment was designed to fill this gap. For strings that were five or seven characters long, letter recognition probability was measured as a function of fixation position and of the position of the letter in a string. We used uppercase Xs with a single uppercase target letter placed at the various possible positions in the string.

\section{EXPERIMENT 1 Letter Identification}

In this experiment, letter visibility was measured as a function of position in a string and of fixation position on that string. The letter string was presented tachistoscopically with backward masking. The effects of two different types of mask were compared. Both consisted of hash marks (\#) but differed in length. In previous VP studies, two different masks were used. A short mask, only as long as the stimulus word, was used in the studies of Brysbaert (1994), Brysbaert et al. (1996), Grainger et al. (1992, Experiment 2), Montant, Nazir, and Poncet (1998), and Nazir et al. (1992). Farid and Grainger (1996) and Kajii and Osaka (2000) used a long mask that covered all the possible stimulus locations. In the other studies cited, stimuli were not masked.

\section{Method}

Subjects. Thirty-six students at the University of Provence participated in the experiment for partial course credit. Their mean age was 20 years and 5 months. Two of them were left-handed. Four were 
male, 32 female. All of them reported normal or corrected-tonormal vision and were native speakers of French.

Design. String length, mask type, letter position, and fixation position were manipulated. The length of the series of letters was manipulated as a between-subjects factor. In the seven-letter condition, mask type was also varied between subjects. In the five-letter condition, this factor was varied across blocks within subjects, and the order of the masks was counterbalanced. All other factors were manipulated as within-subjects factors. These were (1) letter position, with all possible locations of the target letter being tested, and (2) fixation position, with fixations occurring on each character position in the string. The target letters were the consonants B, C, D, F, $\mathrm{H}, \mathrm{G}, \mathrm{J}, \mathrm{K}, \mathrm{L}, \mathrm{M}, \mathrm{N}, \mathrm{P}, \mathrm{R}, \mathrm{S}$, and T, presented in uppercase, thus providing 15 measurements for each experimental condition per subject. Each target letter was embedded at all possible positions in a string of uppercase Xs, to give a string with a total length of five or seven. In the five-letter condition this led to a 2 (mask order) $\times 2$ (mask type) $\times 5$ (letter position) $\times 5$ (fixation position) design, with 750 trials per subject and 12 subjects. In the seven-letter condition, this led to a 2 (mask type) $\times 7$ (letter position) $\times 7$ (fixation position) design, with 735 trials per subject and 24 subjects, since mask type was manipulated between subjects.

Procedure. Each trial began with the appearance of two vertically aligned fixation lines, one character position above and below the stimulus location. The subjects were instructed to fixate between these lines. After $1 \mathrm{sec}$, the fixation lines disappeared and were replaced by the stimulus. To force fixation on a certain position, the stimulus was displaced horizontally relative to the fixation lines. After an individually adjusted presentation time, the stimulus was masked by a series of hash marks. The mask either could be two characters longer than the stimulus or could cover all the possible presentation locations plus one character to the left and right (i.e., there were two types of mask). The subject's task was to indicate which letter he or she had seen, by typing the corresponding letter on the computer keyboard. After the subject's response, the screen was cleared, and a new trial began following a 500-msec delay. No time pressure was imposed, and after every 150 trials, the subjects were given a short break. A practice session of, maximally, 115 trials preceded the experiment. During this phase, presentation times were adjusted to the subject's level of performance to avoid floor or ceiling effects. To do this, only fixations on one of the three central letter positions were used, and letters could appear only at the three central letter positions in the string. Every 9 trials, the mean score of the subject was computed. If more than $70 \%$ of the responses were correct, presentation duration was made $16 \mathrm{msec}$ shorter. If fewer than $60 \%$ of the responses were correct, presentation time was lengthened by $16 \mathrm{msec}$. The presentation time could not become less than $50 \mathrm{msec}$ or more than $100 \mathrm{msec}$. Average presentation duration was $83 \mathrm{msec}$ for the five-letter strings and $97 \mathrm{msec}$ for the seven-letter strings.

Visual presentation conditions. The experiment took place in a brightly lit room, using a Pentium III PC with a 15 -in. color screen. The subjects sat with their eyes approximately $50 \mathrm{~cm}$ from the screen. No chinrest was used. Stimuli were presented as white letters (rgb: 63, 63, 63) on a black screen using the $\mathrm{xm} 9 \mathrm{x} 15 \mathrm{~b}$ font of the gcc Unix compiler $(9 \times 15$ pixels, boldfaced). The approximate visual angles of the stimuli were the following. One character was $0.32^{\circ}$ wide and $0.41^{\circ}$ high. Interletter space was $0.09^{\circ}$. In the five-letter condition, this made the stimulus $1.97^{\circ}$ wide, the short mask $2.79^{\circ}$ wide, and the long mask $4.39^{\circ}$. In the seven-letter condition, this gave a $2.79^{\circ}$-wide stimulus and $3.57^{\circ}$ - and $6.03^{\circ}$-wide masks.

\section{Results}

The results of the five-letter and seven-letterconditions could not be analyzed in one analysis of variance (ANOVA), because of the different number of levels of the fixation position and letter position factors. A mask $\times$ fixation position $\times$ letter position ANOVA was carried out for the percentage of correct recognition scores in the sevenletter condition, and a mask order $\times$ mask $\times$ fixation position $\times$ letter position ANOVA was carried out for the

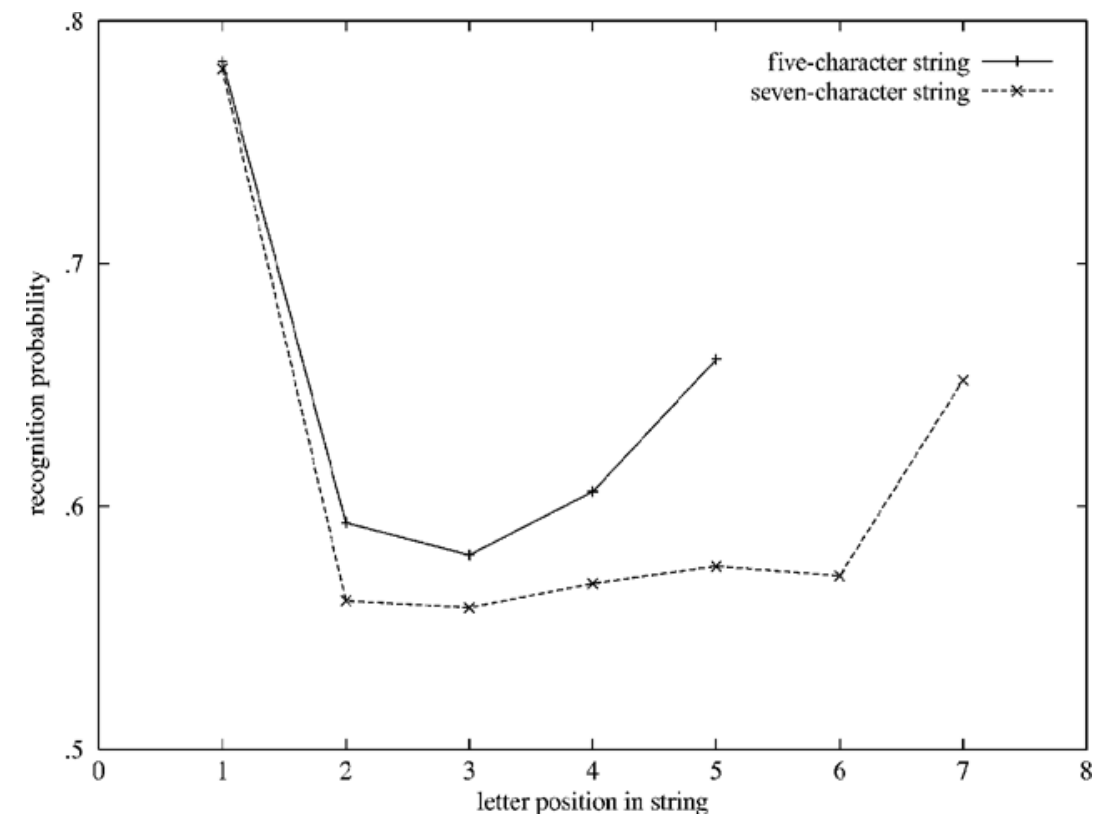

Figure 1. Probability of correct letter recognition as a function of letter position, collapsed over fixation positions. 
five-letter condition. The type of mask in the seven-letter condition and the mask order factor in the five-letter condition were handled as between-subjects factors; all the other factors were within-subjects repeated measures. In the following discussion, the position of the relevant letter in the string will be referred to as letter position. Positions will be counted from left to right, beginning with one. The position of a letter relative to fixation will be counted in letter positions, with a negative index for locations left of fixation. Letters that are not at the extremes of a string will be referred to as inner letters, and the first and the last letters will be referred to as outer letters.

Seven-letter ANOVA. There was a main effect of letter position $[F(6,132)=52.34, p<.001]$. Figure 1 shows that this was due mainly to end effects. The outer letters were more visible than the inner letters $[F(1,22)=157.30$, $p<.001]$, and the first letter was more visible than the last $[F(1,22)=37.73, p<.01]$.

The main effect of fixation position was also highly significant $[F(6,132)=40.92, p<.001]$ and is presented graphically in Figure 2. Letter visibility averaged over all possible letter positions varied as a function of initial fixation position, following an inverse $\mathrm{U}$-shaped function presenting a highly significant quadratic trend $[F(1,22)=$ $182.72, p<.001]$. The function relating average letter visibility with initial fixation position was highly symmetric, ${ }^{3}$ with no sign of a linear trend $(F<1)$. The effect of fixation position was caused by the drop in recognition rate as initial fixation moved from the center to the periphery.

The effect of mask type did not reach significance $[F(1,22)=2.41]$. This factor did not interact significantly with letter position $[F(6,132)=1.88]$ or with fixation position $(F<1)$. The third-order interaction of these factors was not significant either $(F<1)$.

There was a significant interaction between letter position and fixation position $[F(36,792)=41.09, p<.001]$. Figure 3 plots probability of correct recognition as a function of the target letter's position relative to fixation. This factor combines the fixation position and the letter position factors and can be computed as letter position fixation position relative to the initial letter. For example, when fixation is on the first letter (1) of a series and the target letter is on the third (3) position, its location will be +2 . With fixation on the second letter (2), the fourth (4) letter will be at location +2 , and so forth. Letters at the same position in a string are connected with a line. This transformation shows that the interaction was caused by the different forms of the curves for the first and the last letters and for the inner letters left or right of fixation.

Five-letter ANOVA. The results for the five-letter strings were similar to those for the seven-letter strings (see Figure 1). The main effect of letter position was significant $[F(4,40)=19.93, p<.001]$. The outer letters were more visible than the inner letters $[F(1,10)=32.22, p<.001]$, and the first letter was more visible than the last $[F(1,10)=$ $16.82, p<.01]$.

The effect of fixation position was once again highly significant $[F(4,40)=27.44, p<.001]$. As can be seen in Figure 2, average letter visibility dropped as initial fixation moved from the center (Position 3 ) to the periphery (Positions 1 and 5). Once again, there was a highly significant quadratic trend in this function $[F(1,10)=169.30$,

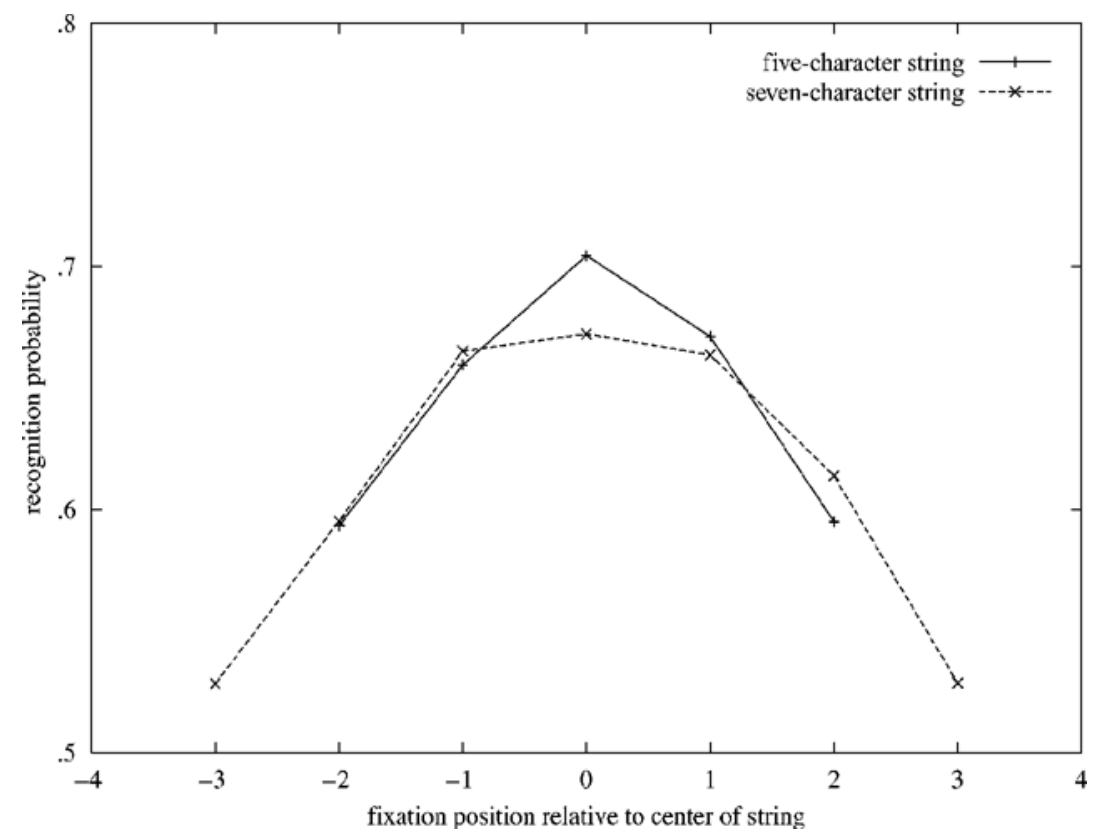

Figure 2. Probability of correct letter recognition as a function of fixation position, collapsed over letter positions. 

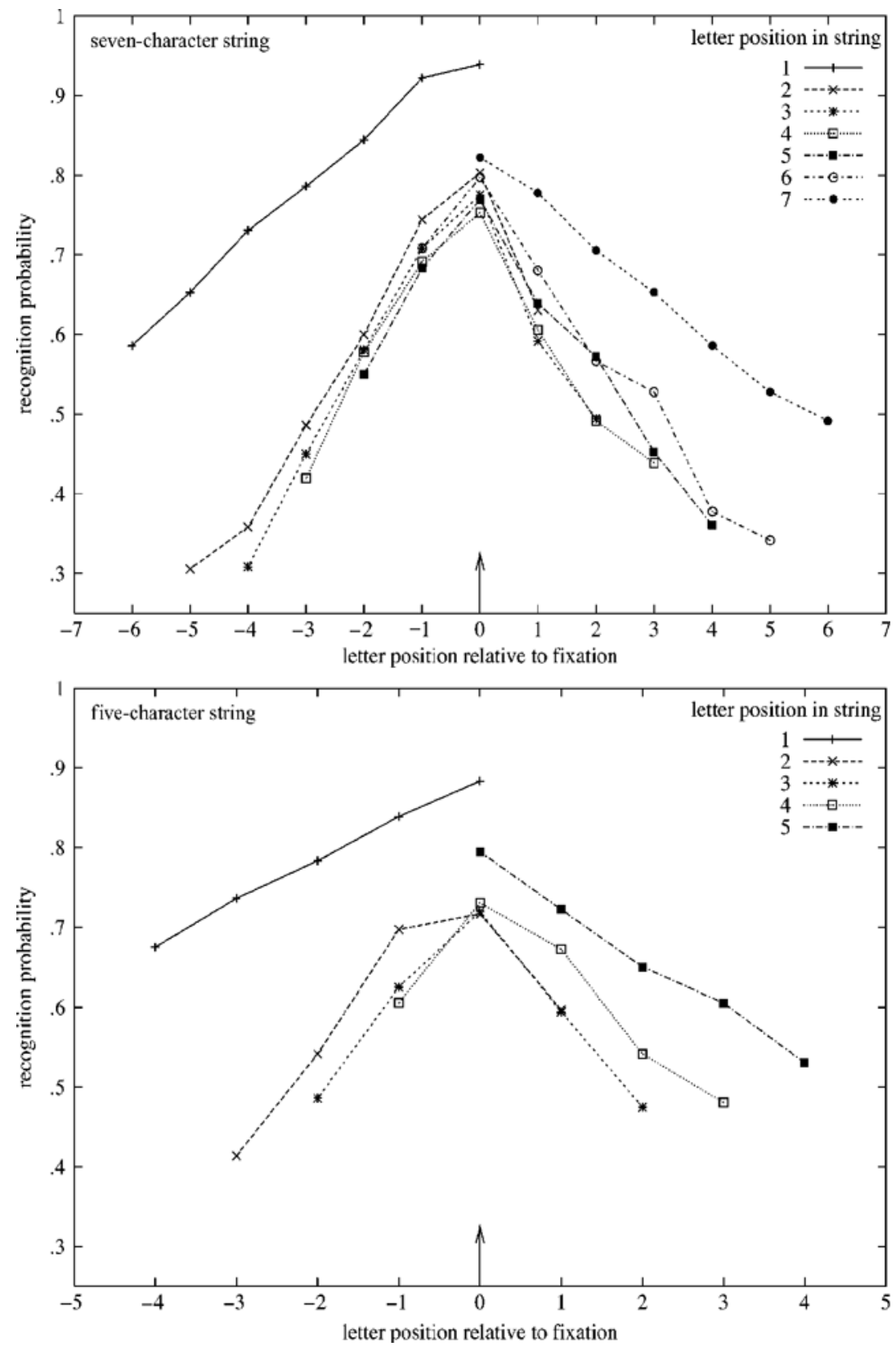

Figure 3. Probability of correct letter recognition as a function of distance to fixation. Letters that are at the same position in a string are connected with a line. Top panel: sevenletter strings. Bottom panel: five-letter strings.

$p<.001]$. As with the seven-letter strings, the letter visibility $\times$ fixation position curve was symmetric and showed no hint of a linear trend $(F<1)$.

The main effect of mask type was not significant $[F(1,10)=1.33]$; nor was the interaction of mask type with letter position $(F<1)$ or with fixation position $[F(4,40)=1.18]$ significant. The triple interaction of mask, letter position, and fixation position was not significant $(F<1)$.

\section{Discussion}

The critical finding of Experiment 1 was a symmetric drop-off in average letter visibility as initial fixation position moved from the center of the stimulus to the periphery. This experiment replicated the well-known end effects and distance-from-fixation effects for letter identification. Both for the five- and the seven-letter strings, the outer letters were easier to identify than the inner letters, and the initial letter was better identified than the final letter. 
Recognition performance for inner letters was mostly a function of distance from fixation. This replicates and extends results from previous research (e.g., Estes et al., 1976; Nazir, Deutsch, Grainger, \& Frost, 2000; Nazir et al., 1992).

The results of Experiment 1 appear to stand in contradiction to prior reports of higher levels of letter visibility in the right visual field (Bouma, 1973; Kajii \& Osaka, 2000; Nazir et al., 1992). However, as was already pointed out in Note 1, the visual presentation conditions were very different in these studies, as compared with the present experiment. In Bouma's experiments and the experiment run by Kajii and Osaka, the entire letter string always fell left or right of a central fixation (at varying levels of eccentricity), and in the experiments of Nazir et al. (1992), fixation was always on the first or the last letter of the string. The conditions tested by Nazir et al. (1992) were actually a subset of the conditions tested in Experiment 1. However, a comparison of the relevant conditions (average visibility for fixations on the first letter vs. fixations on the last letter) showed no significant difference in the present experiment.

In search of possible explanations for these different patterns of letter visibility, we performed a split-half analysis, separating subjects into two groups on the basis of their average letter identification scores. Indeed, the average performance of the subjects tested by Nazir et al. (1992) was lower than the performance of the subjects tested in Experiment 1. The group factor did not interact with effects of fixation position for the five-letter strings $(F<1)$ but did so for the seven-letter strings $[F(6,120)=$ $2.45, p<.05]$. A test for asymmetry in the seven-letter strings, using a linear trend analysis, proved nonsignificant in the upper group $[F(1,10)=2.30]$ and was only marginally significant in the lower group $[F(1,10)=3.56$, $p<.10]$. The lower group tended to have superior scores for fixations to the right of center. Since fixations to the right leave more letters in the left visual field, this trend actually goes in the direction opposite to that observed by Nazir et al. (1992).

It therefore appears that the general context of always having to fixate on either the first or the last letter in a string (i.e., the conditions tested by Nazir et al., 1992) or always having the string presented completely to the left or to the right of fixation (Bouma, 1973; Kajii \& Osaka, 2000 ) induces a specific processing bias that gives rise to a superior visibility for letters presented in the right visual field. Attentional factors are likely to play a role here, and further experimentation could be designed to test this hypothesis. The critical point here is that in Experiment 1, we have tested for letter visibility under visual presentation conditions that are directly comparable to those that will be used to examine the VP effect with word stimuli. This was not the case in prior studies.

We will now examine the letter recognition curves separately for each fixation position for a given string length. These are the data that will be used to predict performance to word stimuli tested in the same conditions.

Figure 4 plots recognition probability as a function of letter position in string, with separate graphs for each fixation position. The shapes of the letter visibility functions vary substantially across the different fixation positions. There are basically two patterns of letter visibility that emerge as fixation position is varied. The first is a $\mathrm{J}$ shaped function or its mirror: Fixations on the most peripheral letters produced a visibility curve in which the first letter was recognized most easily, with a monotonic decline in performance for the letters further in the string, except for the end-letter opposite fixation. The second is W-shaped: When the middle of a seven-letter string was fixated, visibility was greatest for the fixated letter and dropped monotonically for letters further from fixation, except for the two external letters.

Generally speaking, the working hypothesis concerning letter visibility applied by Clark and O'Regan (1999) is supported by the present results. Most important, however, is that we now have an empirically determined set of letter visibility measures for each possible fixation position in five- and seven-letter strings. After testing a large set of fiveand seven-letter words in the following experiment, we will use the letter visibility results of Experiment 1 in conjunction with various measures of lexical constraint in an attempt to predict the performance obtained with word stimuli.

\section{EXPERIMENT 2 Word Identification}

\section{Method}

Subjects. Seventy students at the Université de Provence participated in the experiment, which lasted about half an hour. All were native speakers of French. Their mean age was 20 years and 9 months. Five were male, 4 were left-handed, and all reported normal or corrected-to-normal vision.

Stimuli and Design. Only nouns and adjectives with a written frequency of occurrence between 50 and 150 per million (Imbs, 1971) were used. The 75 five-letter words and the 105 seven-letter words are given in the Appendix. The mean printed frequency of the five-letter words was 87 per million $(S D, 26.5$; range, 50-141), and for the seven-letter words, it was 88 per million $(S D, 25.6$; range, 50-145). The mask factor (short or long masking stimulus) was manipulated as a between-subjects variable. The fixation position factor had five levels for the five-letter words and seven for the sevenletter words. A Latin-square design was used in order to avoid each word's being presented several times to the same subject. The words were classified into groups of 15 such that the mean frequencies and standard deviations of the different groups were about the same. For each mask condition, 35 subjects saw 15 words of each length at every possible fixation position. The Latin square was repeated seven times for the seven-letter words and five times for the five-letter words. Word length was not blocked.

Procedure. The procedure was the same as that in Experiment 1. Each trial began with two vertically aligned fixation lines, which remained on the screen for $1 \mathrm{sec}$. Then the word was presented in uppercase letters for $50 \mathrm{msec}$, followed by a row of hash marks, which covered the word plus one character position to the left and to the right for the short mask and covered all possible letter positions plus one letter to the right and to the left for the long mask. Presentation times were the same for all the subjects in Experiment 2 (given that the majority of the subjects in Experiment 1 were tested at the same stimulus duration, this simplification in procedure was not expected to have a significant impact). After $250 \mathrm{msec}$, the instruction to type in the word was presented. A new trial began $500 \mathrm{msec}$ after the subjects had typed their response and confirmed with the Enter key. The experiment was preceded by a series of 25 practice trials with only five-letter words. The 180 experimental trials were divided into two 

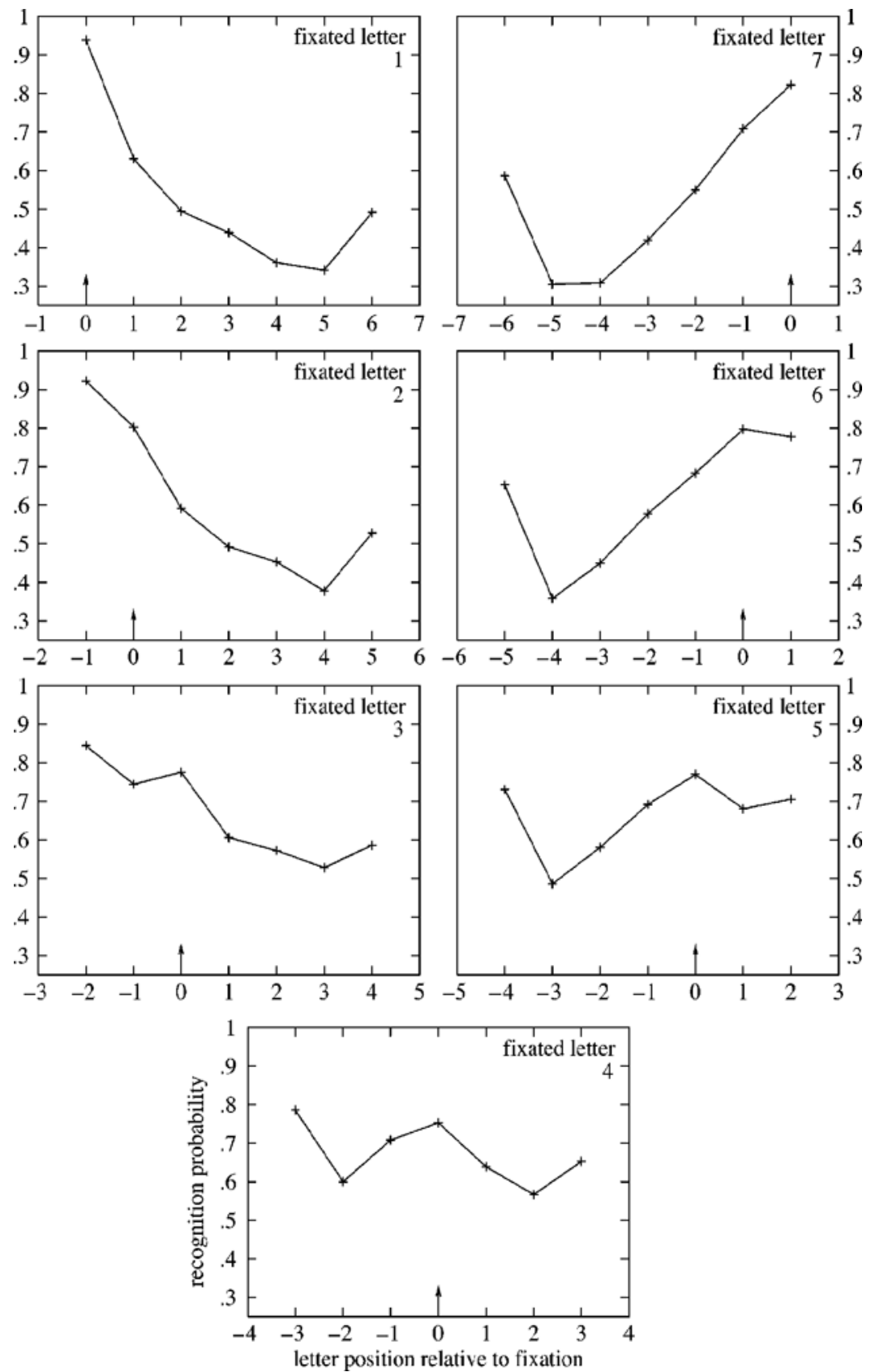

Figure 4A. Probability of correct letter recognition as a function of fixation position and string position for seven-letter strings. Separate graph for each fixation position.

blocks of 90 trials, with a short break in between. No time pressure was imposed. Visual presentation conditions and visual angles of the stimuli were the same as those in Experiment 1.

\section{Results}

ANOVAs were carried out on the word recognition probabilities, with mask type and fixation position as independent variables. Because of the different number of levels of the fixation position factor for the five- and seven-letter words and the use of a Latin-square design, there were four ANOVAs: one for each word length and analyses by subject and by item. Figure 5 shows the word recognition probabilities as a function of fixation position.

Seven-letter words. The effect of fixation position was highly significant $\left[F_{1}(6,408)=156.97, p<.001\right.$; $\left.F_{2}(6,624)=152.60, p<.001\right]$ and presented a strong quadratic trend $\left[F_{1}(1,68)=356.79, p<.001 ; F_{2}(1,104)=\right.$ $560.45, p<.001]$. Performance was slightly lower in the long-mask condition, but this was not significant in the analysis by subjects $\left[F_{1}<1 ; F_{2}(1,104)=9.73, p<.01\right]$. 

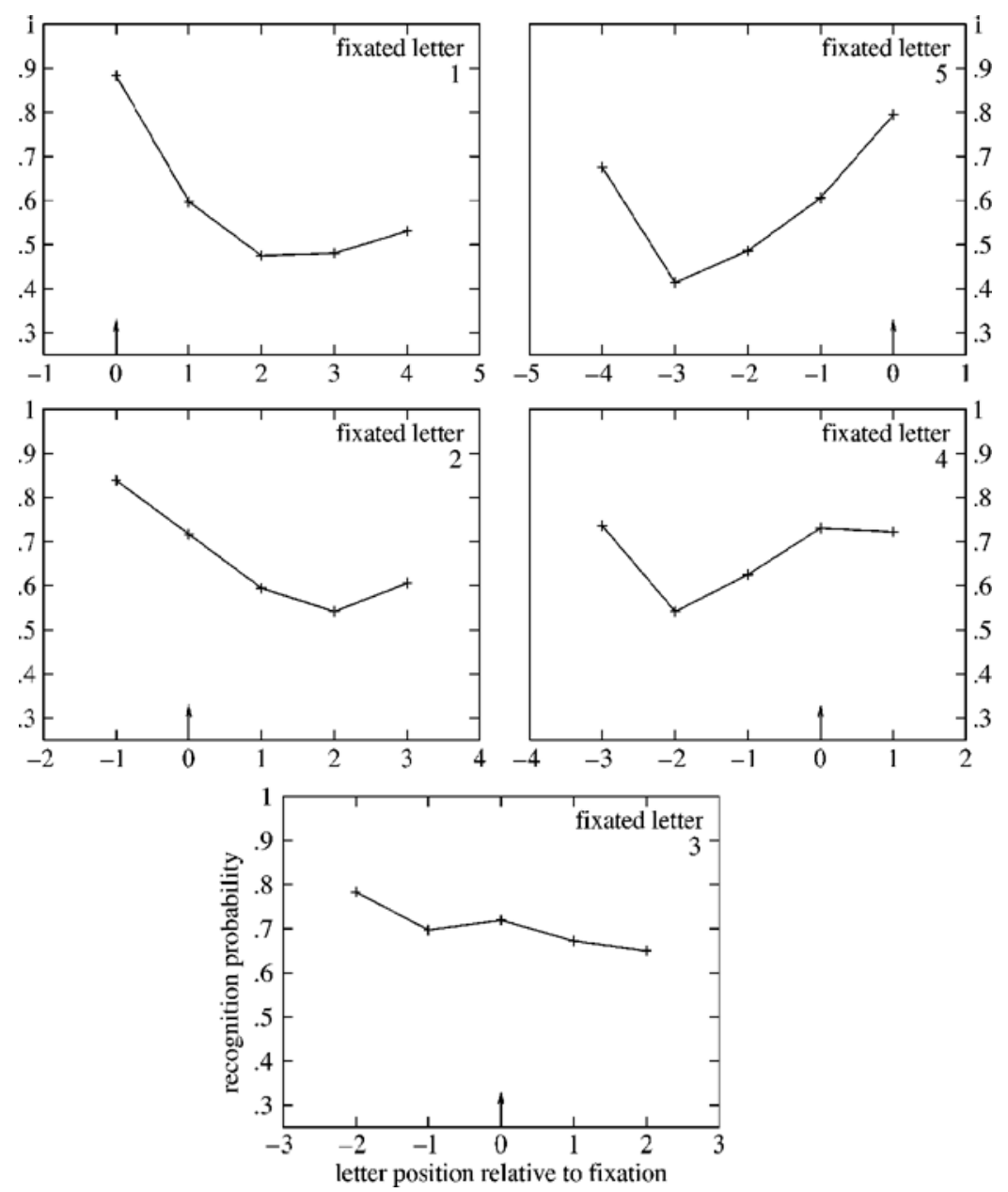

Figure 4B. Probability of correct letter recognition as a function of fixation position and string position for five-letter strings. Separate graph for each fixation position.

Mask type did not interact with the effects of fixation position $\left(F_{1}<1 ; F_{2}<1\right)$. There was a significant linear trend in the VP function $\left[F_{1}(1,68)=180.36, p<.001 ; F_{2}(1,104)=\right.$ $200.89, p<.001]$, indicating that the function relating fixation position to recognition rate was asymmetric. Fixations left of center generated higher levels of performance, as compared with fixations right of center.

Five-letter words. The results for the five-letter words paralleled those of the seven-letter words: a significant effect of fixation position $\left[F_{1}(4,272)=64.49, p<.001\right.$; $\left.F_{2}(4,296)=76.67, p<.001\right]$ with a highly significant quadratic trend $\left[F_{1}(1,68)=173.68, p<.001 ; F_{2}(1,74)=\right.$ $208.11, p<.001]$, no effect of mask type $\left(F_{1}<1 ; F_{2}<1\right)$, and no interaction between these factors $\left[F_{1}<1\right.$; $\left.F_{2}(4,296)=1.65\right]$. Again, there was a significant linear trend in the VP function $\left[F_{1}(1,68)=44.14, p<.001\right.$; $\left.F_{2}(1,74)=53.20, p<.001\right]$.

\section{Discussion}

For both word lengths, the classic asymmetric inverse U-shaped function relating initial fixation position and word recognition probability was found. This function was found to be highly asymmetric for both the five-letter and the seven-letter words, thus replicating prior findings. Furthermore, in Experiment 2, the size of the masking stimulus did not influence the pattern of results. Prior research with pattern-masked isolated words had used different types of mask: a short mask, only as long as the stimulus word (Brysbaert, 1994; Brysbaert et al., 1996; Grainger et al., 1992; Montant et al., 1998; Nazir et al., 1992), or a long mask covering all possible stimulus locations (Farid \& Grainger, 1996; Kajii \& Osaka, 2000). Our results show that mask size does not interact with the VP effect. It should be noted, however, that the present study used only backward masking. Use of a forward mask would clearly change the situation, with a small mask acting as a potential attentional cue for the upcoming word.

\section{COMBINED ANALYSES OF EXPERIMENTS 1 AND 2}

The major finding of the present study was the presence of a strong asymmetry in the VP function for word stimuli (Experiment 2) that contrasts with the symmetric func- 


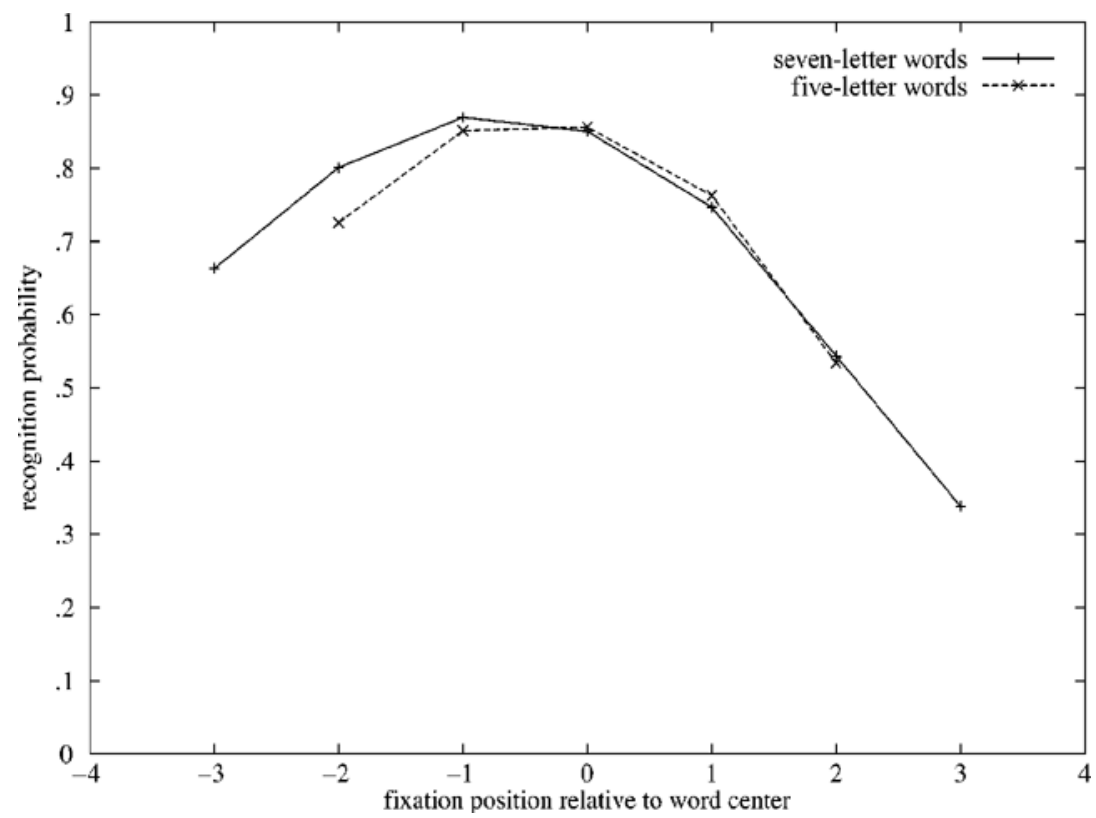

Figure 5. Probability of correct word recognition as a function of fixation position relative to word center.

tion found for average letter identification scores (Experiment 1). This implies that the typical word-beginning advantage observed with word stimuli cannot be accounted for in terms of variations in letter visibility. The main objective of the present study, however, was to examine whether the letter visibility data from Experiment 1 could be used in conjunction with some measure of lexical constraint in order to predict the VP curves obtained for the word stimuli in Experiment 2 (see Kajii \& Osaka, 2000,
Legge, Mansfield, \& Chung, 2001, and Nazir et al., 1998, for similar attempts). Three types of constraint analysis are to be presented here: (1) The number of words compatible with a given number of the most visible letters (determined empirically) at each fixation position were calculated following Clark and O'Regan (1999); (2) the average letter visibility measures (fixation position $\times$ position in string) were used to adjust the letter-word excitation parameter in the interactive activation model (IAM;

Table 1

Results of Lexical Constraint Measures Based on (1) Ambiguity Given the Most Visible Letters Using an Absolute (amb A) and a Relative (amb R) Position Type Count, (2) Simulations Run on the Interactive Activation Model (IAM), and (3) Letter Visibility Times Conditional Probabilty of Letters, Using Absolute $(\mathbf{v} \times \mathbf{p}$ A) and Relative $(v \times p$ R) Position Token Counts

\begin{tabular}{|c|c|c|c|c|c|c|c|}
\hline fixpos & obs & Lvis & amb A & amb R & IAM & $\mathrm{v} \times \mathrm{p} \mathrm{A}$ & $\mathrm{v} \times \mathrm{pR}$ \\
\hline \multicolumn{8}{|c|}{ Seven-Letter Words } \\
\hline 1 & .66 & .53 & 2.80 & 17.19 & 22.37 & 0.1186 & 0.008512 \\
\hline 2 & .80 & .60 & 2.80 & 17.19 & 21.80 & 0.1341 & 0.009183 \\
\hline 3 & .87 & .67 & 2.15 & 11.69 & 20.95 & 0.1520 & 0.009666 \\
\hline 4 & .85 & .67 & 1.78 & 14.76 & 20.95 & 0.1524 & 0.009570 \\
\hline 5 & .75 & .66 & 1.87 & 15.44 & 21.00 & 0.1522 & 0.009458 \\
\hline 6 & .54 & .61 & 3.60 & 20.98 & 21.36 & 0.1415 & 0.008659 \\
\hline 7 & .34 & .53 & 3.60 & 20.98 & 22.61 & 0.1192 & 0.007538 \\
\hline \multicolumn{8}{|c|}{ Five-Letter Words } \\
\hline 1 & .73 & .59 & 1.41 & 15.76 & 22.21 & 0.0832 & 0.008076 \\
\hline 2 & .85 & .66 & 1.48 & 15.76 & 20.66 & 0.0927 & 0.008377 \\
\hline 3 & .86 & .70 & 1.14 & 8.55 & 20.10 & 0.0995 & 0.008522 \\
\hline 4 & .76 & .67 & 1.39 & 10.29 & 20.63 & 0.0931 & 0.008163 \\
\hline 5 & .53 & .59 & 1.39 & 10.29 & 21.24 & 0.0795 & 0.007438 \\
\hline
\end{tabular}

Note-The average probability of correct letter identification (Lvis) for each fixation position (fixpos) are given (Experiment 1), as well as the probability of correct word identification values from Experiment 2 (obs). 
Table 2

Results of Regression Analyses Using the Different Lexical Constraint Measures Provided in Table 1 and the Letter Identification Data of Experiment 1 to Predict the Word Recognition Data of Experiment 2

\begin{tabular}{lccc}
\hline \multicolumn{1}{c}{ Measure } & Intercept & Weight & $r^{2}$ \\
\hline \multicolumn{4}{c}{ Seven-Letter Words } \\
Mean letter visibility & -0.660 & 0.721 & \\
Ambiguity (abs) & 1.219 & -0.211 & .719 \\
Ambiguity (rel) & 1.532 & -0.050 & .768 \\
IAM & 4.944 & -0.197 & .516 \\
Vis $\times$ prob (abs) & -0.522 & 8.724 & .471 \\
Vis $\times$ prob (rel) & -1.455 & 239.7 & .911 \\
& Five-Letter Words & & \\
Mean letter visibility & -0.608 & 0.784 & .615 \\
Ambiguity (abs) & 1.107 & -0.266 & .072 \\
Ambiguity (rel) & 0.674 & 0.006 & .023 \\
IAM & 2.507 & -0.084 & .265 \\
Vis $\times$ prob (abs) & -0.539 & 14.34 & .768 \\
Vis $\times$ prob (rel) & -1.787 & 312.1 & .987 \\
\hline
\end{tabular}

Note-Abs, absolute; rel, relative; IAM, interactive activation model; vis $\times$ prob, letter visibility times conditional probability.

McClelland \& Rumelhart, 1981); and (3) positional letter frequency values were combined with the average letter visibility scores.

These different calculations reflect different ways of estimating lexical constraint. Following Clark and O'Regan (1999), the ambiguity measure takes only the most salient letters into consideration. On the other hand, both the letter frequency model and the IAM simulation take all letters into consideration, each one weighted by its visibility. In the IAM, the individual letters interact to provide a joint constraint on lexical activation, whereas in the letter frequency model, the individual letters act independently, providing a summed measure of spatial redundancy for a given string of letters.

\section{Lexical Ambiguity Given Most Visible Letters}

By using the letter visibility data presented in Figure 4, the four most visible letters were selected for each word and each fixation position tested in Experiment 2. From these four letters, we calculated the total number of French words that are compatible with these letters, using both an absolute position and a relative position count. In the absolute position count (also used by Clark \& O'Regan, 1999), letter position depends on string length (e.g., second letter of a five-letter word). On the other hand, our relative position count is length independent and uses three position codes: first letter, last letter, and inner letter pair.

These ambiguity scores for each fixation position and word length are given in Table 1. Linear regressions were then performed using the mean recognition probability per fixation position and word length observed in Experiment 2 (see Table 2). The data predicted by these linear regressions are given, along with the observed data, in Figure 6.

The results of these calculations show a very slight advantage for the relative position coding scheme when am- biguity is measured. However, the fits with the empirical data are not very good, and only the seven-letter predictions show something resembling the observed asymmetry in the VP function. Ambiguity measures taking word frequency into consideration showed poorer fits with the data (as estimated by $r^{2}$ ), and a position coding scheme in which inner letters could appear at any internal position in any order produced even worse fits. The problem with these ambiguity measures is that the most visible letters are the same for fixations on the first and second letters and for fixations on the sixth and seventh letters of a seven-letter word. This means that ambiguity does not vary across these two adjacent positions. The problem also applies to Clark and O'Regan's (1999) original measure, since the same letters are used to define ambiguity for fixations on the first and second letters of a seven-letter string (Letters 1, 2, 3, and 7).

\section{Interactive Activation Model}

The multiple read-out version (Grainger \& Jacobs, 1996) of the IAM was used in the present simulations. It has a lexicon of French five-letter words used in previous simulation work (Grainger \& Jacobs, 1996; A. M. Jacobs \& Grainger, 1992), and a new lexicon of French sevenletter words was added for the present study. Letter-word excitation strength is modified via the ESTR parameter of the model. For each letter position in a string of a given length and for each fixation position, we set the ESTR parameter equal to the probability of correct letter identification measured in Experiment 1. The parameter settings of the original model (McClelland \& Rumelhart, 1981) were maintained, except for the letter-word parameter, which was set at .045 for the seven-letter simulations, as compared with .07 for the five-letter simulations.

For each word tested in Experiment 2, we measured the number of cycles to reach a fixed criterion level of activation (0.68) for the different settings of the ESTR parameter. The means per condition are given in Table 1 . These were transformed via linear regression to predict the data obtained in Experiment 2. The results of this analysis are shown in Figure 7 and Table 2. The model predicts a rather symmetrical VP function that is not in line with the observed data.

\section{Positional Letter Frequency}

This analysis was motivated by a finding reported by Grainger and Jacobs (1993). These authors found that masked partial priming of visual word recognition was well predicted by the positional frequencies of the letters shared by a partial prime and the target word. Thus, given a target word like TABLE, differences in the effects of partial primes such as TA\%LE and TABL\%, are reflected in differences in the summed positional frequencies of letters TA-L-E, as compared with T-A-B-L. The greater the positional letter frequency, the smaller the priming effect relative to an unrelated prime condition.

In the following analysis, we used the percentage of correct letter identification scores for each letter position 

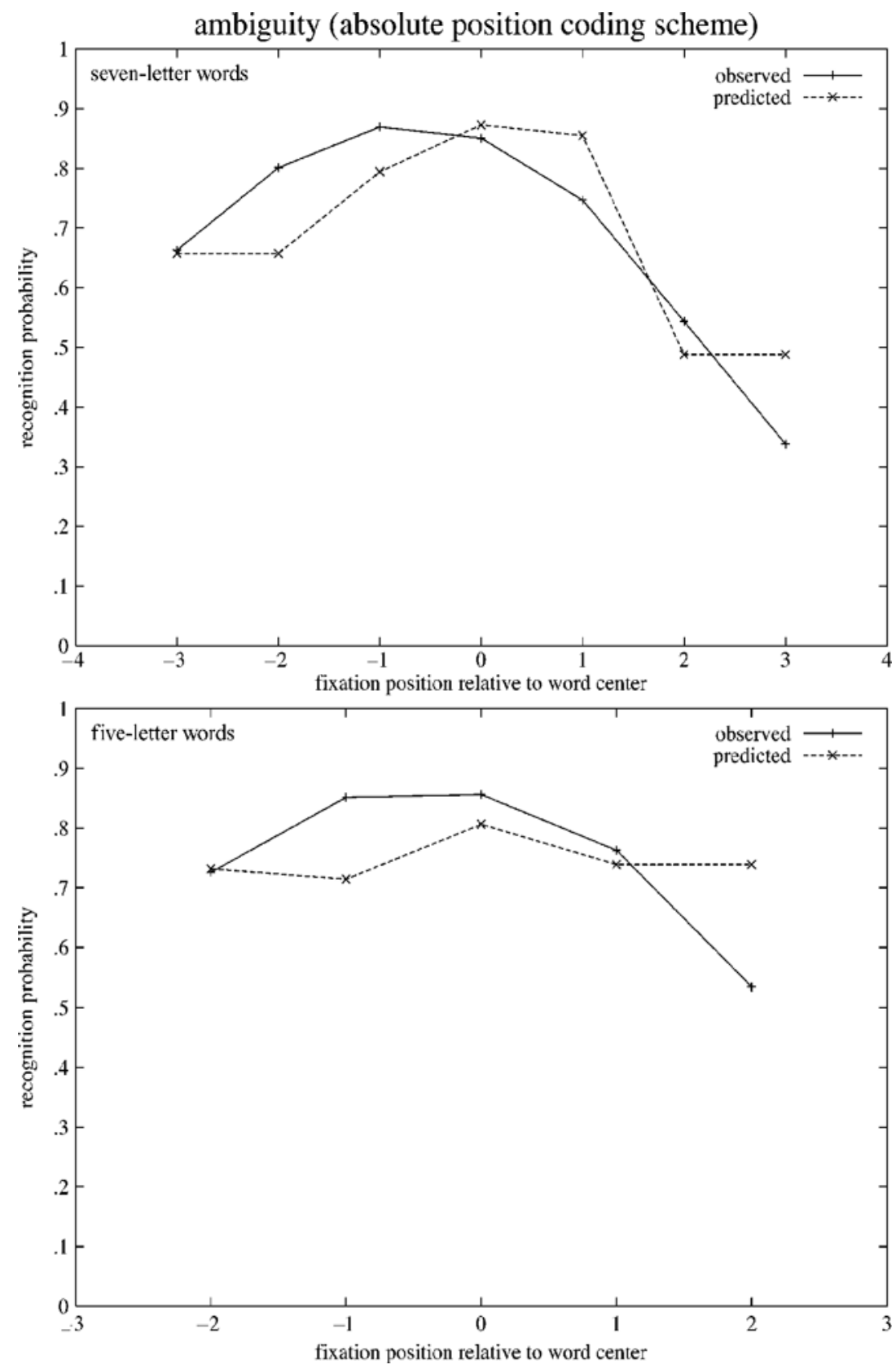

Figure 6A. Predictions derived from the ambiguity measure using the four most visible letters (the data from Experiment 2 are replotted for comparison) for absolute position coding scheme. Top panel: seven-letter words. Bottom panel: five-letter words.

and fixation position tested in Experiment 1 and combined these with positional letter frequencies calculated using French word frequency counts (Imbs, 1971). Two types of positional frequency were calculated. Absolute positional frequency refers to the number of times a given letter appears in a given position in a string of fixed length (e.g., the number of times $\mathrm{T}$ occurs as the second letter of a five-letter word). Relative position frequency was calculated independently of string length, using a three-slot scheme: first letter, last letter, and inner letter. Only the results of token frequency counts are given here (i.e., counts in which letter frequency is weighted by word frequency values).

For each fixation position, the visibility scores associated with each letter position were combined with the positional letter frequencies of the target words tested in Experiment 2 , using the equation given below. More precisely, a conditional probability associated with each letter in a 
ambiguity (relative position coding scheme)
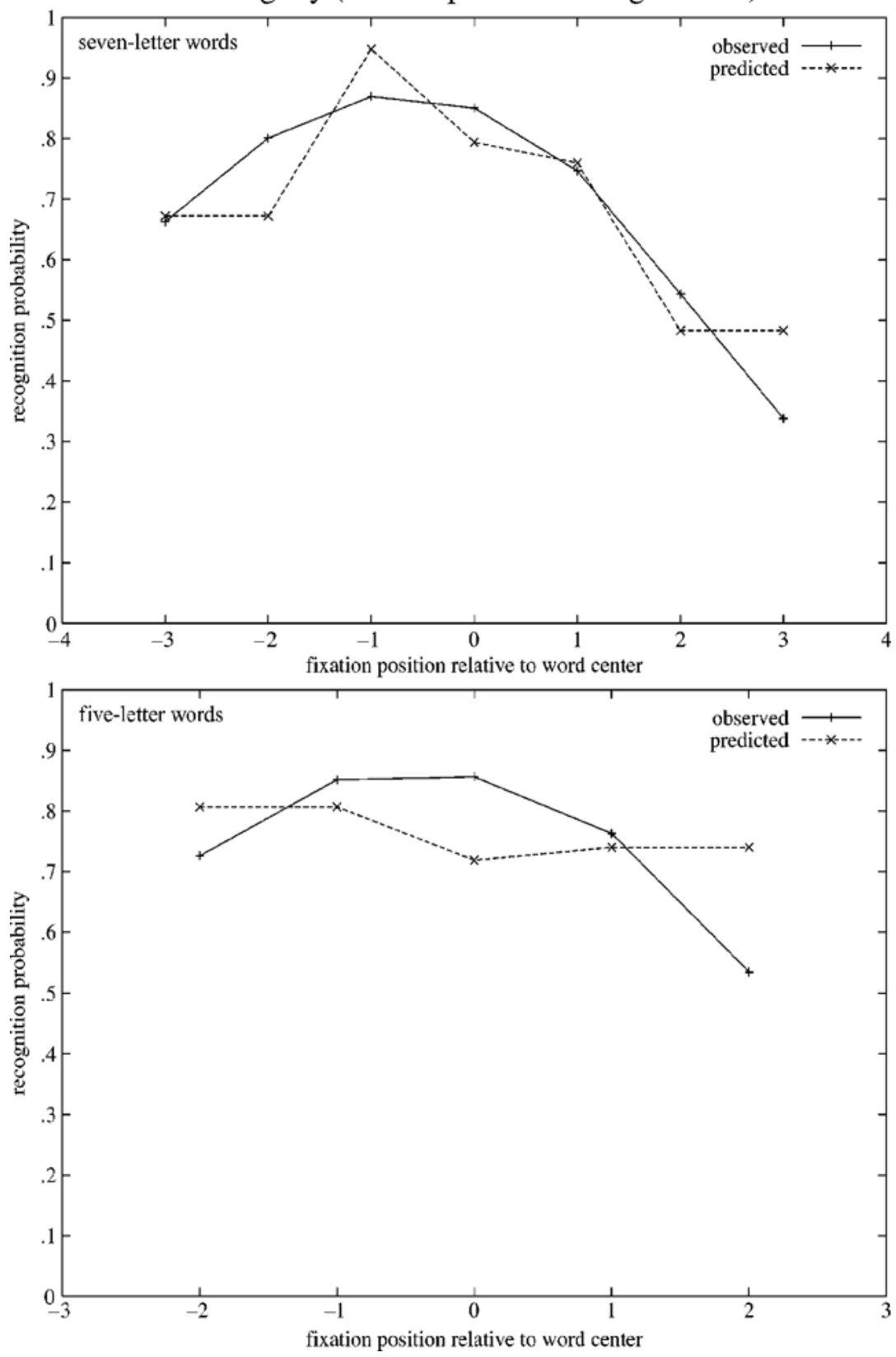

Figure 6B. Predictions derived from the ambiguity measure using the four most visible letters (the data from Experiment 2 are replotted for comparison) for relative position coding scheme.

given stimulus word was first calculated. This is equal to the frequency of the stimulus word ( $W_{\text {freq }}$ ) divided by the positional frequency of that letter $\left(L_{\text {freq }}\right)$ at a specific position $\mathrm{p}$ and indexes the probability that a given letter in a given position belongs to the stimulus word. This conditional probability was multiplied by the letter visibility score for that position $\left(L_{\mathrm{vis}(\mathrm{p})}\right)$, and these values were summed across all letters in a given target word of length $n$ to give a total conditional probability $\times$ visibility measure for each fixation position and each word 4 :

$$
\sum_{\mathrm{p}=1 . . n}\left[W_{\text {freq }} / L_{\text {freq }(\mathrm{p})}\right] \times L_{\mathrm{vis}(\mathrm{p})} .
$$

Table 1 provides the means across all words of a given length of these weighted conditional probabilities per fixation position. The results of a linear regression of these values on the data of Experiment 2 are shown in Figures 
IAM simulation results
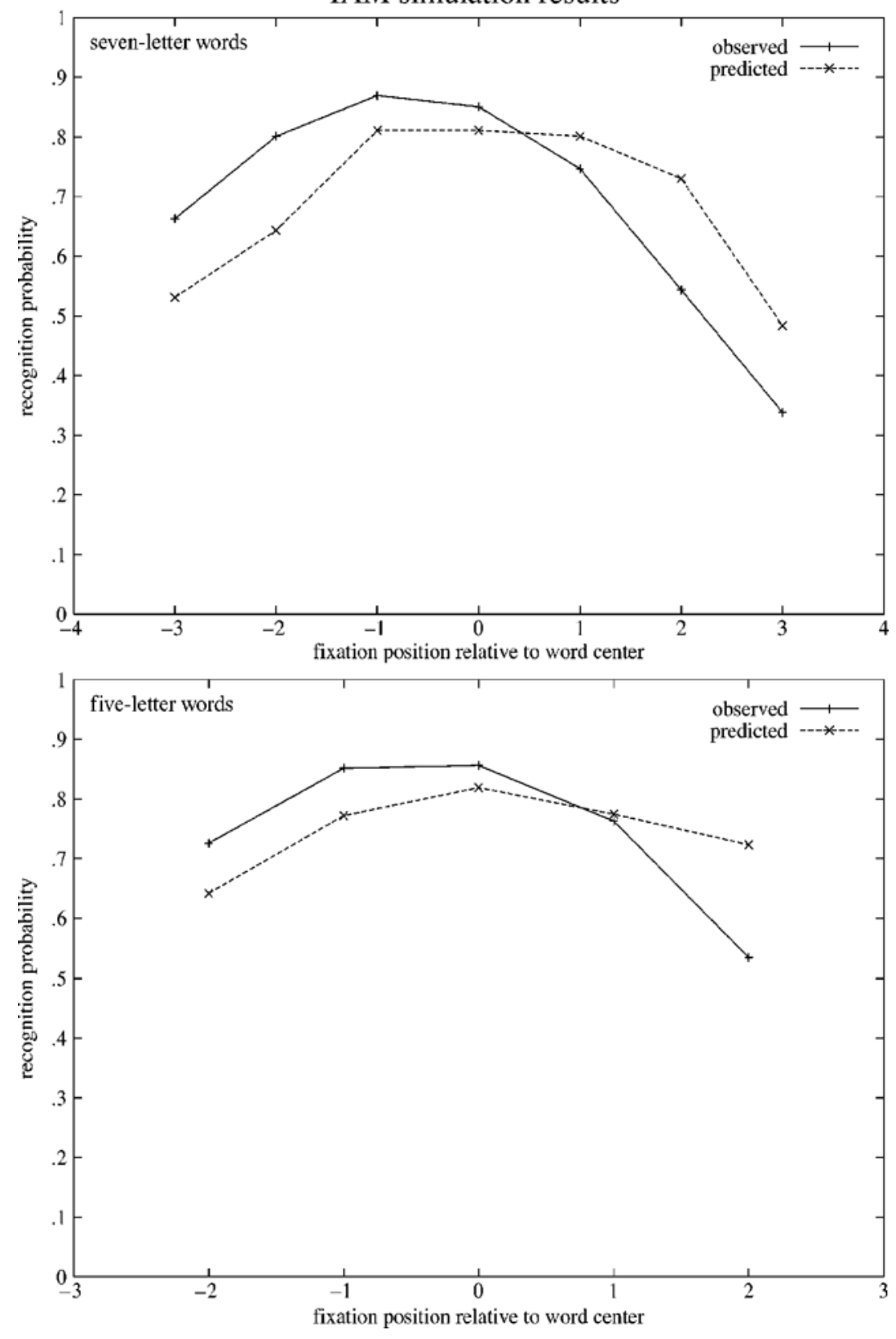

Figure 7. Results of simulations run on the interactive activation model (IAM). Top panel: seven-letter words. Bottom panel: five-letter words. (The data from Experiment 2 are replotted for comparison.)

8A (absolute position) and 8B (relative position) and Table 2. It is interesting to note that the absolute position scheme generates a pattern that resembles the predictions of the IAM (compare Figure 7 and Figure 8A). In fact there is almost a perfect overlap with these two sets of predictions. Both generate highly symmetrical VP functions. On the other hand, the relative position scheme very accurately reflects the word identification curves, particularly for the five-letter stimuli. Like the observed data, the
VP curves are asymmetrical, with a word-initial bias. Relative position coding of letter-in-string position provides a more accurate account of the empirical VP function, as compared with absolute position coding.

\section{GENERAL DISCUSSION}

The present study confirmed the asymmetrical form of the function that relates initial fixation position in a word 


\section{visibility $\times$ probability (absolute position coding scheme)}
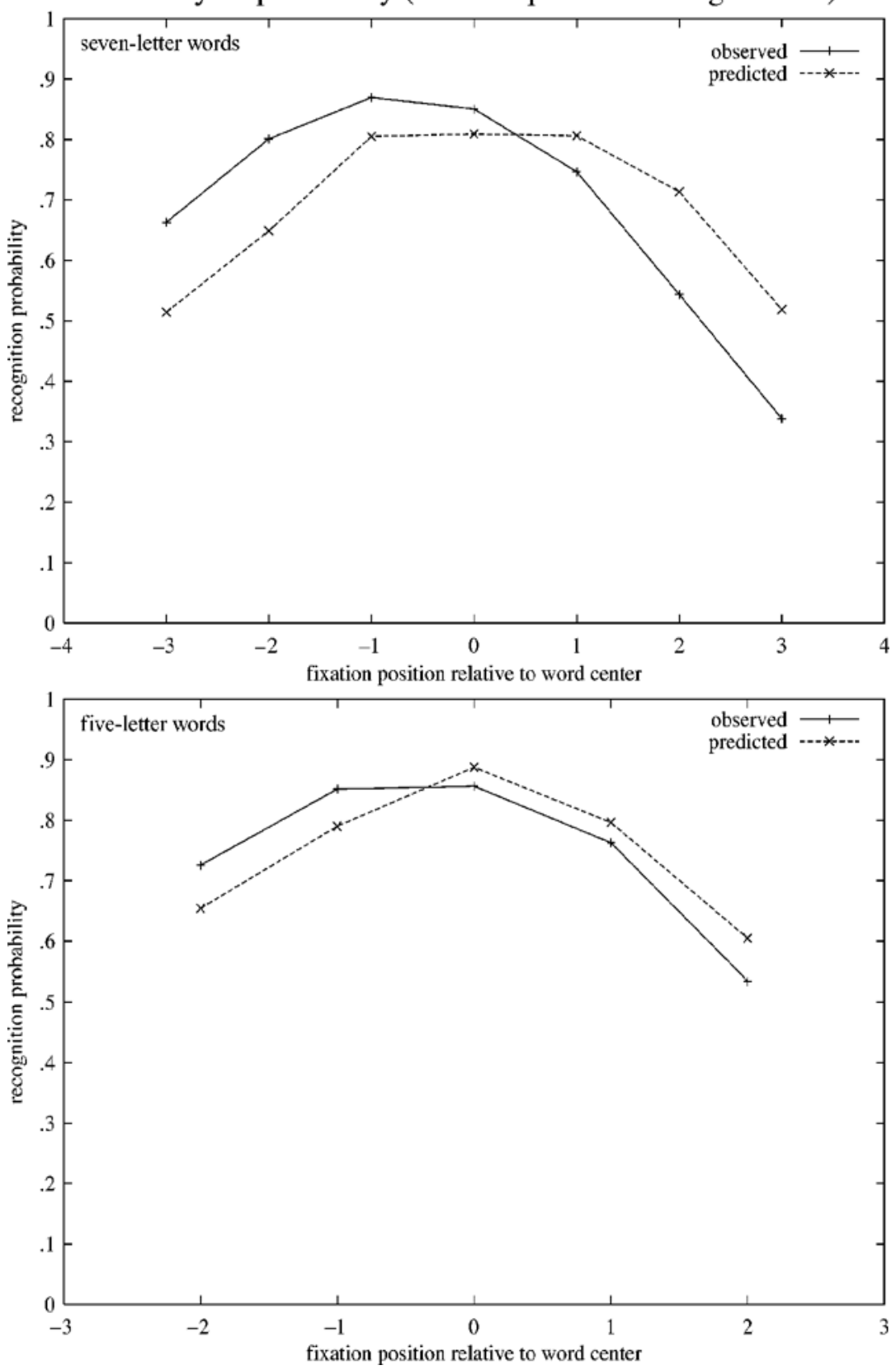

Figure 8A. Predictions derived from a constraint measure based on positional letter frequency (the data from Experiment 2 are replotted for comparison) for absolute position coding scheme. Top panel: seven-letter words. Bottom panel: five-letter words.

and the ease with which that word is recognized (the VP function). Five- and seven-letter French words were systematically recognized at higher levels of accuracy with fixations left of the word's center, as compared with fixations right of center. The results of Experiment 1 demonstrated that variations in letter visibility cannot explain the asymmetry observed with word stimuli. Average letter visibility was shown to vary as a function of initial fixa- tion position, following a highly symmetrical inverse Ushaped function.

The main goal of the present study was to examine whether the amount of lexical constraint provided by the most visible letters in a word might be the basis of the observed asymmetry in the VP function. This has been a central hypothesis since the introduction of the VP paradigm by O'Regan et al. (1984). However, prior research 

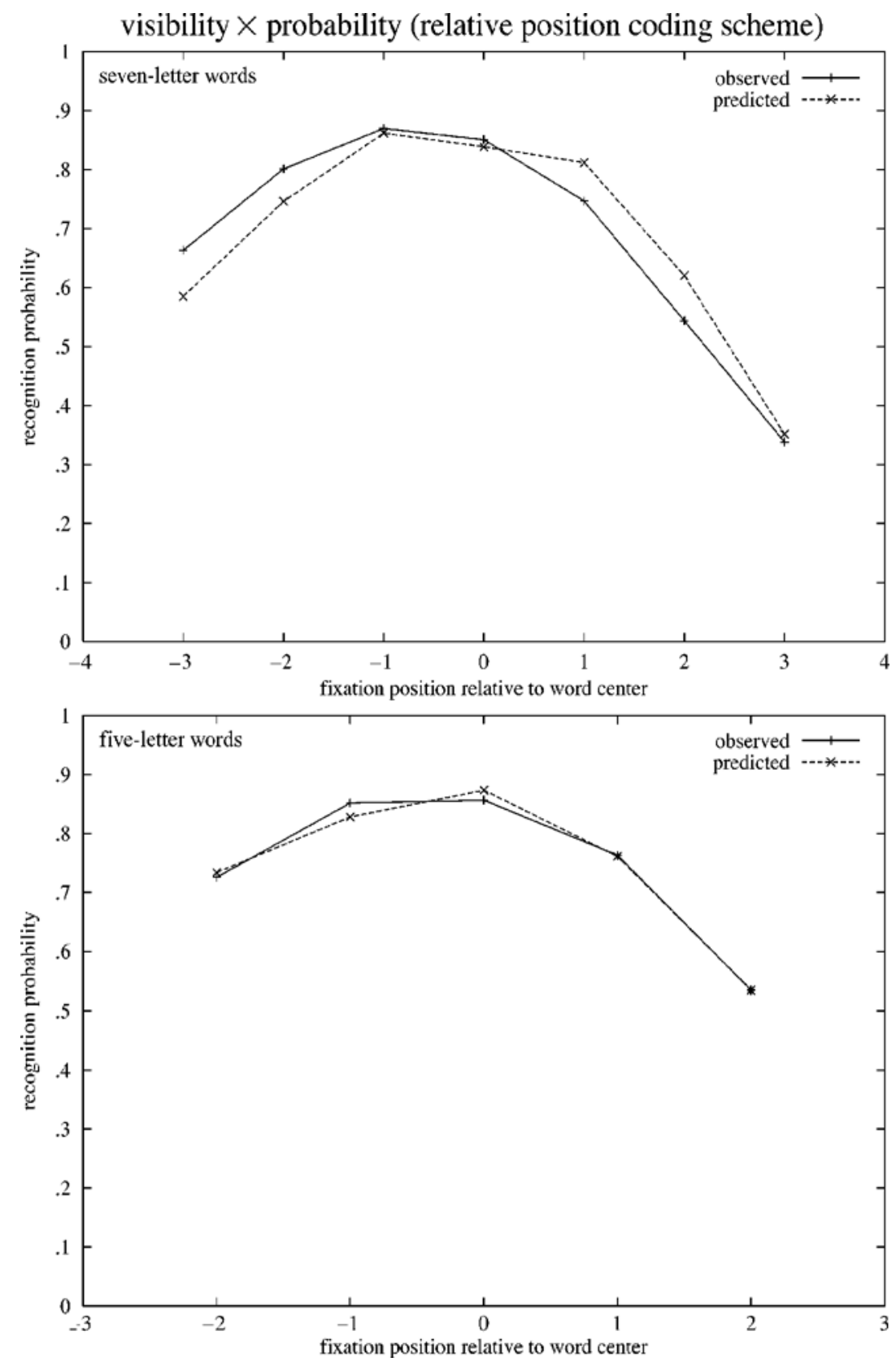

Figure 8B. Predictions derived from a constraint measure based on positional letter frequency (the data from Experiment 2 are replotted for comparison) for relative position coding scheme. Top panel: seven-letter words. Bottom panel: five-letter words.

whose aim was to test this hypothesis has found only relatively minor influences of lexical constraint. Thus, when words with higher levels of constraint provided by letters to the right of center were tested, the leftward bias was indeed reduced, but a rightward bias was never obtained (Brysbaert et al., 1996; Holmes \& O'Regan, 1987; O'Regan et al., 1984). Only the study by Farid and Grainger (1996) actually produced a shift in the asymmetry as a function of the position of critical information in the word.
In this particular study, the root morpheme of affixed Arabic words was either at the beginning (suffixed words) or at the end (prefixed words), and the VP function had its optimum in the part of the word where the root morpheme was located (see also Deutsch \& Rayner, 1999, for a similar result in Hebrew).

The failure to find strong effects of lexical constraint in languages such as English and French could be due to the precise measures of constraint that have been used in the 
past. Clark and O'Regan (1999) performed a statistical analysis using computerized dictionaries of English and French. They counted the total number of words that were compatible with the two outer letters plus the two letters closest to fixation. The plots of ambiguity as a function of fixation position were very similar to empirical VP curves. The theoretical work of Clark and O'Regan therefore suggests that appropriate shifts in the VP function should be obtained when their measure of lexical constraint are applied.

Rather than directly testing the ambiguity measure used by Clark and O'Regan (1999; this could be the basis of further work), in the present study, we sought empirical evidence for their assumptions concerning variations in letter visibility as a function of fixation location. Generally speaking, our data show that these assumptions hold, although in a few conditions the final letter in a string was barely more visible than inner letters away from fixation. In any case, a distinct initial letter advantage dominated the pattern of results (see Figure 1). Most important, when combined with certain statistical measures of stimulus redundancy, these letter visibility data quite accurately predicted the VP functions obtained with word stimuli in Experiment 2 . The fits with the word data varied as a function of the specific measure of constraint or redundancy that was adopted. ${ }^{5}$ In what follows, we will use these particular results to examine how orthographic information is coded during printed word perception.

\section{Lexical Constraint and Stimulus Redundancy}

In Experiment 2 of the present study, a large set of fiveletter and seven-letter French words was tested with a standard VP manipulation. The observed data were then compared with various measures of lexical constraint and stimulus redundancy based on the patterns of letter visibility observed in Experiment 1.

In an ambiguity analysis based on Clark and O'Regan's (1999) proposal, we calculated the number of words that were compatible with the four most visible letters in the stimulus word. The results of this analysis were, at most, suggestive. For in the seven-letters words, the ambiguity measures using a relative position scheme did show an asymmetry in the VP function, but the overall fit with the empirical data was quite poor. The relative position calculation (first letter, last letter, and inner letter pair appearing at any internal position in words of varying length) was slightly better than the absolute position calculation. Token counts, as opposed to type counts, only decreased the fit, as did a measure in which inner letters could appear at any internal position in any order.

A letter-based measure of constraint using positional letter frequencies (thus calculating spatial, as opposed to sequential, redundancy) generated the best fit with the data. The relative success of this particular measure is in line with the prior observation of Grainger and Jacobs (1993) showing positional letter frequency to be the best predictor of priming effects in a masked partial-priming paradigm. Thus, with the target word TABLE, the efficiency of $\mathrm{T} \% \mathrm{BLE}$ as a prime stimulus depended on the positional frequencies of T, B, L, and E. The higher these frequencies, the smaller the priming effect, as compared with an unrelated prime condition. Just as in the present calculations, these positional letter frequencies provide a good estimate of the number of other words that will compete for identification with the target word.

These data therefore suggest that the orthographic coding of letter strings treats each letter independently and activates whole-word representations proportionally to the amount of independent evidence provided by each letter in the stimulus. In such a model, a whole-word representation receives activation even if it shares only a single letter with the stimulus. This is, in fact, what happens in McClelland and Rumelhart's (1981) IAM. Simulations run on the IAM showed that it can accurately capture the influence of variations in letter visibility on printed word perception by simply adjusting the strength of feature-toletter excitatory connections. This produces a perfectly symmetrical VP function, just like the function generated by average letter visibility. However, the type of lexical constraint that is built into the IAM via letter-word connectivity and word-word inhibition does not allow it to capture the observed asymmetry in the VP function for words. The results of the other ambiguity analyses suggest that it might be the letter position coding scheme of the model that is causing the problem. The IAM applies a length-dependentabsolute position coding scheme, whereas the results of the ambiguity and redundancy analyses systematically show a superiority for relative position coding, as opposed to absolute position coding.

\section{Letter Position Coding}

The present study provides further evidence in favor of a coding scheme for letter-in-string position that uses relative, rather than absolute, position in the string. The coding scheme that provided the best fit with the VP function for word stimuli was one in which the first and the last letters of the string are coded precisely for these positions, but independently of string length, and in which the inner letters are coded as being inner letters in a given order, but at any possible inner location.

There is independent evidence in favor of this type of letter position coding scheme. Using the masked prime paradigm with brief prime exposures, Peressotti and Grainger (1999) found that facilitatory orthographic priming was sensitive to the relative position of letters shared by prime and target stimulus, but not to their absolute position. Thus, for example, the French target word BALCON was primed just as effectively by the stimulus BLCN as by the stimulus B-LC-N, when compared with an unrelated prime condition. On the other hand, there was no significant priming as soon as the relative order of the letters was disrupted, such as in the primes BCLN and NLCB.

These data converge in favor of a position coding scheme that accurately codes the positions of the first and the last letters in the string and assigns a relative string-internal position to the other letters. So when processing the stim- 
ulus BLCN, the orthographic processor "knows" that B is the first letter, that $\mathrm{N}$ is the last letter, and that $\mathrm{L}$ and $\mathrm{C}$ are somewhere in the middle in that order. Whitney (2001) has described a model of letter position coding that is compatible with these assumptions. We are currently developing an extension of the IAM (McClelland \& Rumelhart, 1981) that implements this new letter position coding scheme. Future simulation work will show whether such a modification will allow the model to capture the asymmetric form of the VP function.

\section{Asymmetry in the VP Function}

Finally, the present study shows that a combination of letter visibility and one specific measure of stimulus redundancy (positional letter frequency) quite accurately captures the typical asymmetric form of the VP function obtained with word stimuli. Other factors, such as hemispheric specialization and perceptual learning, may contribute to the VP function. Applying Occam's razor, however, any account of the observed asymmetry should remain as simple as possible until there is convincing evidence to the contrary. The literature summarized in the introduction to this study has not yet provided such convincing evidence. Furthermore, assigning stimulus redundancy a critical role in explaining the asymmetry in the VP function is in line with the data obtained from eye movement paradigms, showing that the distribution of information in a word influences the pattern of eye fixations in the word (e.g., Pynte, 1996).

With respect to the letter visibility data, although the average recognition scores showed a symmetric VP curve (see Figure 2), the W-shaped curves for central fixations (see Figure 4) did show a slight leftward superiority that has been found in previous unpublished work by the second author and by Nazir et al. (2000). In these studies, in which central fixations were used, letters left of fixation were identified better than letters right of fixation. It is interesting to note that Nazir et al. (2000) found that this asymmetry in letter identification performance was reversed for Hebrew, a language read from right to left. This implies that the asymmetry is influenced by reading direction and could be due to the manner in which attention is deployed across a letter string when its center is fixated.

What is critical, however, with respect to the implications of the present study is that when letter visibility is measured for all fixation positions and for all positions of the target in the string, a symmetrical VP function for average letter visibility is found. Variations in letter visibility alone cannot account for the VP function obtained with words. One other factor must be at play. Following Clark and O'Regan (1999), the present study suggests that one critical additional factor is a particular measure of stimulus redundancy that indexes the likelihood that a given letter in the target word does indeed belong to that word. Word recognition performance is optimized when the most visible letters have the highest conditional probabilities. Further research could test words having the highest conditional probabilities for letters at the end, rather than at the beginning, of the word.

\section{REFERENCES}

Anstis, S. M. (1974). A chart demonstrating variations in acuity with retinal position. Vision Research, 14, 589-592.

Bouma, H. (1973). Visual interference in the parafoveal recognition of initial and final letters of words. Vision Research, 13, 767-782.

BRYSBAERT, M. (1994). Interhemispheric transfer and the processing of foveally presented stimuli. Behavioural Brain Research, 64, 151-161.

Brysbaert, M., Vitu, F., \& Schroyens, W. (1996). The right visual field advantage and the optimal viewing position effect: On the relation between foveal and parafoveal word recognition. Neuropsychology, 10, 385-395.

Clark, J. J., \& O'Regan, J. K. (1999). Word ambiguity and the optimal viewing position in reading. Vision Research, 39, 843-857.

Coltheart, M., Davelaar, E., Jonasson, J. T., \& Besner, D. (1977). Access to the internal lexicon. In S. Dornic (Ed.), Attention and performance VI (pp. 535-555). Hillsdale, NJ: Erlbaum.

Deutsch, A, \& RAYNER, K. (1999). Initial fixation location effects in reading Hebrew words. Language \& Cognitive Processes, 14, 393-421.

Dunn-Rankin, P. (1978, January). The visual characteristics of words. Scientific American, 238, 122-130.

Estes, W. K., Allmeyer, D. H., \& Reder, S. M. (1976). Serial position functions for letter identification at brief and extended exposure durations. Perception \& Psychophysics, 19, 1-15.

FARID, M., \& Grainger, J. (1996). How initial fixation position influences visual word recognition: A comparison of French and Arabic. Brain \& Language, 53, 351-368.

GRAINGER, J. (1990). Word frequency and neighborhood frequency effects in lexical decision and naming. Journal of Memory \& Language, 29, 228-244.

GRAINGER, J., \& JACOBS, A. M. (1993). Masked partial-word priming in visual word recognition: Effects of positional letter frequency. Journal of Experimental Psychology: Human Perception \& Performance, 19, 951-964.

Grainger, J., \& JAcoBs, A. M. (1996). Orthographic processing in visual word recognition: A multiple read-out model. Psychological Review, 103, 518-565.

Grainger, J., O’Regan, J. K., Jacobs, A. M., \& Segui, J. (1992). Neighborhood frequency effects and letter visibility in visual word recognition. Perception \& Psychophysics, 51, 49-56.

Holmes, V. M., \& O'Regan, J. K. (1987). Decomposing French words. In J. K. O’Regan \& A. Lévy-Schoen (Eds.), Eye movements: From physiology to cognition (pp. 459-466). Amsterdam: North-Holland.

Huckauf, A., Heller, D., \& Nazir, T. A. (1999). Lateral masking: Limitations of the feature interaction account. Perception \& Psychophysics, 61, 177-189.

ImBS, P. (1971). Études statistiques sur le vocabulaire français: Dictionnaire des fréquences. Vocabulaire littéraire des XIXe et XXe siècles. Paris: Librairie Marcel Didier.

JACOBS, A. M., \& GRAINGER, J. (1992). Testing a semistochastic variant of the interactive activation model in different word recognition experiments. Journal of Experimental Psychology: Human Perception \& Performance, 18, 1174-1188.

JACOBS, R. J. (1979). Visual resolution and contour interaction in the fovea and periphery. Vision Research, 9, 1187-1195.

KAJII, N., \& OsaKa, N. (2000). Optimal viewing position in vertically and horizontally presented Japanese words. Perception \& Psychophysics, 62, 1634-1644.

Legge, G. E., Mansfield, J. S., \& Chung, S. T. (2001). Psychophysics of reading: XX. Linking letter recognition to reading speed in central and peripheral vision. Vision Research, 41, 725-743.

McClelland, J. L., \& Rumelhart, D. E. (1981). An interactive activation model of context effects in letter perception: Pt. I. An account of basic findings. Psychological Review, 88, 375-407.

McConkie, G. W., Kerr, P. W., Reddix, M. D., Zola, D., \& Jacobs, A. M. (1989). Eye movement control during reading: II. Frequency of refixating a word. Perception \& Psychophysics, 46, 245-253.

Montant, M., Nazir, T., \& Poncet, M. (1998). Pure alexia and the viewing position effect in printed words. Cognitive Neuropsychology, 15, 93-140.

NAZIR, T. A. (1991). On the role of refixations in letter strings: The influence of oculomotor factors. Perception \& Psychophysics, 49, 373-389. 
NAzIR, T. A. (2000). Traces of print along the visual pathway. In A. Kennedy, R. Radach, D. Heller, \& J. Pynte (Eds.), Reading as a perceptual process (pp. 3-22). Amsterdam: Elsevier.

Nazir, T. A., Deutsch, A., Grainger, J., \& Frost, R. (2000). The role of early perceptual learning in reading. Abstracts of the Psychonomic Society, $\mathbf{5}, 83$.

Nazir, T. A., Heller, D., \& Sussmann, C. (1992). Letter visibility and word recognition: The optimal viewing position in printed words. Perception \& Psychophysics, 52, 315-328.

NaziR, T. A., JACOBS, A. M., \& O'Regan, J. K. (1998). Letter legibility and visual word recognition. Memory \& Cognition, 26, 810-821.

O'Regan, J. K. (1981). The convenient viewing position hypothesis. In D. F. Fisher, R. A. Monty, \& J. W. Senders (Eds.), Eye movements, cognition, and visual perception (pp. 289-298). Hillsdale, NJ: Erlbaum.

O'REgAN, J. K., \& JACOBS, A. M. (1992). The optimal viewing position effect in word recognition: A challenge to current theory. Journal of Experimental Psychology: Human Perception \& Performance, 18, 185-197.

O'Regan, J. K., Lévy-Schoen, A., Pynte, J., \& Brugaillè̀e, B. (1984). Convenient fixation location within isolated words of different length and structure. Journal of Experimental Psychology: Human Perception \& Performance, 10, 250-257.

Peressotti, F., \& Grainger, J. (1999). The role of letter identity and letter position in orthographic priming. Perception \& Psychophysics, 61, 691-706.

Pynte, J. (1996). Lexical control of within-word eye movements. Journal of Experimental Psychology: Human Perception \& Performance, 22, 958-969.

RAYNER, K. (1979). Eye guidance in reading: Fixation locations within words. Perception, 8, 21-30.

Rayner, K., Well, A. D., \& Pollatsek, A. (1980). Asymmetry of the effective visual field in reading. Perception \& Psychophysics, 27, 537-544.
Vitu, F., O'Regan, J. K., \& Mittau, M. (1990). Optimal landing position in reading isolated words and continuous text. Perception \& Psychophysics, 47, 583-600.

Whitney, C. (2001). How the brain encodes the order of letters in a printed word: The SERIOL model and selective literature review. Psychonomic Bulletin \& Review, 8, 221-243.

\section{NOTES}

1. It should be noted that in the letter visibility experiments run by Bouma (1973), Nazir et al. (1992), and Kajii and Osaka (2000), the entire string of letters was always presented to the left or to the right of a central fixation point. Eccentricity relative to the central fixation was varied in Bouma's study, and in the Nazir et al. (1992) study, fixation was always on the first or the last letter of the string.

2. An orthographic neighbor of a given word is defined as any other word of the same length that differs by a single letter, respecting letter position (Coltheart, Davelaar, Jonasson, \& Besner, 1977).

3. In the present study, a linear trend analysis will be used to test for asymmetry in the viewing position function. In the present situation, this amounts to testing for a difference in performance for fixations left of center versus fixations right of center.

4. Legge et al. (2001) have recently applied a very similar measure in their efforts to predict reading speed from letter recognition accuracy.

5. It should be noted that a recent study with Japanese readers of hirigana script (Kajii \& Osaka, 2000) failed to accurately predict the viewing position function in word stimuli as a function of letter visibility and lexical constraint. A satisfactory fit was obtained only by adding a third factor compensating for the higher visibility of outer letters in a string. The reason for this could be the incomplete measure of letter visibility that was used in their study, the particular measure of lexical constraint that was adopted (based on initial or final trigrams), or both.

\section{APPENDIX \\ Stimuli Tested in Experiment 2}

\section{Seven-Letter Words}

absence, absurde, analyse, arrière, article, artiste, attache, attaque, attente, aveugle, blanche, branche, capable, central, cerveau, chaleur, chapeau, complet, conseil, contact, couloir, courage, crainte, cuisine, culture, curieux, défense, délicat, demande, docteur, domaine, douceur, émotion, employé, endroit, énergie, enfance, épreuve, essence, éternel, étrange, extrême, fatigue, feuille, février, fortune, honneur, horizon, horreur, immense, inquiet, inutile, italien, janvier, juillet, justice, langage, lecteur, logique, machine, maladie, malheur, mariage, matière, médecin, mémoire, méthode, miracle, mission, moderne, moindre, morceau, mystère, nerveux, octobre, opinion, oreille, orgueil, origine, ouvrier, parfait, parlant, passant, paysage, peintre, période, progrès, qualité, réponse, réserve, respect, révolte, sauvage, seconde, société, sommeil, souffle, suprême, surface, système, tableau, terrain, théâtre, trouble, univers, village, violent, voiture

\section{Five-Letter Words}

appel, avril, boite, calme, carte, chair, choix, clair, court, crime, crise, croix, début, digne, divin, drame, drôle, éclat, école, élève, envie, épais, étude, exact, ferme, folie, foret, fruit, genou, glace, gorge, haine, herbe, héros, hiver, honte, hôtel, jambe, lampe, large, leçon, léger, lèvre, lourd, masse, motif, neige, noble, nuage, odeur, oncle, pente, pluie, plume, poche, poids, poste, rayon, règle, repos, revue, riche, roman, russe, sable, salon, série, somme, style, tache, tante, texte, titre, trait, unité, usage, utile, vague, verre, voile

(Manuscript received September 10, 2001; revision accepted for publication May 1, 2002.) 